\title{
First Odin sub-mm retrievals in the tropical upper troposphere: ice cloud properties
}

\author{
P. Eriksson, M. Ekström, B. Rydberg, and D. P. Murtagh \\ Department of Radio and Space Science, Chalmers University of Technology, Gothenburg, Sweden \\ Received: 3 July 2006 - Published in Atmos. Chem. Phys. Discuss.: 13 September 2006 \\ Revised: 8 January 2007 - Accepted: 17 January 2007 - Published: 25 January 2007
}

\begin{abstract}
More accurate global measurements of the amount of ice in thicker clouds are needed to validate atmospheric models and sub-mm radiometry can be an important component in this respect. A cloud ice retrieval scheme for the first such instrument in space, Odin-SMR, is presented here. Several advantages of sub-mm observations are shown, such as low influence of particle shape and orientation, and a high dynamic range of the retrievals. In the case of Odin-SMR, only cloud ice above $\approx 12.5 \mathrm{~km}$ can be measured. The present retrieval scheme gives a detection threshold of about $4 \mathrm{~g} / \mathrm{m}^{2}$ above $12.5 \mathrm{~km}$ and does not saturate even for thickest observed clouds $\left(>500 \mathrm{~g} / \mathrm{m}^{2}\right)$. The main retrieval uncertainties are the assumed particle size distribution and cloud inhomogeneity effects. The overall retrieval accuracy is estimated to be $\sim 75 \%$. The retrieval error is judged to have large random components and to be significantly lower than this value for averaged results, but high fixed errors can not be excluded. However, a firm lower value can always be provided. Initial results are found to be consistent with similar Aura MLS retrievals, but show important differences to corresponding data from atmospheric models. This first retrieval algorithm is limited to lowermost Odin-SMR tangent altitudes, and further development should improve the detection threshold and the vertical resolution. It should also be possible to decrease the retrieval uncertainty associated with cloud inhomogeneities by detailed analysis of other data sets.
\end{abstract}

\section{Introduction}

A major uncertainty in the prediction of the future climate is the current poor understanding of cloud processes (IPCC, 2001), where clouds in the tropical upper troposphere are of particular concern. This, since the radiative fluxes are

Correspondence to: P. Eriksson

(patrick.eriksson@chalmers.se) largest in the tropical region and clouds at high altitudes have the strongest influence on outgoing longwave radiation (Okhert-Bell and Hartmann, 1992). Furthermore the response of such clouds to changing surface temperatures is unclear (see e.g. Genio and Kovari, 2002) and these clouds are most likely a key factor for upward transport of air into the stratosphere (Corti et al., 2006) through the upper tropical troposphere (Fueglistaler and Baker, 2006), a phenomenon not completely understood.

A better treatment of clouds in atmospheric modelling requires improved satellite observations, but even to provide accurate data for such a basic parameter as the ice water content (IWC) is a challenging task. Roughly speaking, a remote sounding measurement of cloud ice will primarily be sensitive to particles having a size similar to the wavelength used. This means that a single-wavelength observation will only "sample" a smaller fraction of the possible particle size range (about $10^{-6}-10^{-2} \mathrm{~m}$ ). To deduce an IWC value from this observation thus requires assumptions on the relative number of particles of different sizes, the particle size distribution (PSD). The problem is that the PSD is not a constant quantity, as shown by in-situ measurement campaigns (Heymsfield and Platt, 1984; McFarquhar and Heymsfield, 1997; Heymsfield et al., 2002).

An ideal sensor for cloud ice measurements would accordingly perform observations over a wide range of wavelengths, but such an instrument is yet a hope for the future. To make things worse, present satellite techniques operate at the far ends of the interesting wavelength range, either in the optical/thermal-IR region (e.g. Winker and Trepte, 1998; Stubenrauch et al., 1999) or the mm-wave range (e.g. Hong et al., 2005; Wu et al., 2005). This should be compared to suggestions for a dedicated cloud ice instrument based on a mm/sub-mm (170-900 GHz) radiometer (Evans et al., 2002), preferably complemented with a few IR channels. The sub-mm part is judged as essential as it combines good cloud penetration capability and sensitivity to most important

Published by Copernicus GmbH on behalf of the European Geosciences Union. 

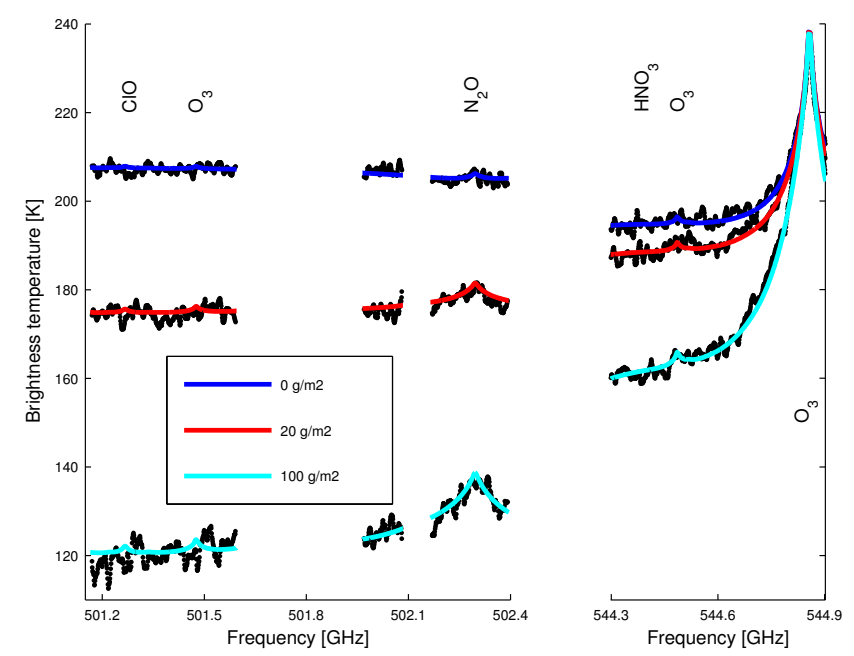

Fig. 1. Simulated and measured spectra of the Odin-SMR stratospheric mode. Tangent altitude is $7 \mathrm{~km}$. Solid (coloured) lines are simulated spectra for different cloud ice columns. The cloud layer is assumed to extend between 12 and $15 \mathrm{~km}$, with the ice vertically equally distributed. The dots (black) represent examples of measured spectra (at $10 \mathrm{MHz}$ resolution, compared to the nominal value of $2 \mathrm{MHz}$ ). The main gas transitions found inside the bands are indicated, with discernible emission originating in the stratosphere. The gas absorption inside the troposphere is highly dominated by water vapour, which is here seen as a spectrally flat "continuum".

particle size range (Evans et al., 1998). The instrument operates in a down-looking geometry, as high horizontal resolution and swath width are highly important aspects, while existing sub-mm satellite sensors are both limb sounders. The longer propagation paths in limb sounding, combined with high gaseous absorption, limits the operational altitude range of sub-mm channels, and the emphasis for cloud ice retrievals moves towards longer wavelengths.

The sub-mm radiometer (SMR) on-board the Odin satellite was launched in 2001 and became then the first satellite instrument for atmospheric sounding in this wavelength region (Murtagh et al., 2002). Odin-SMR is a limb sounder and software for rigorous simulations of this observation geometry including polarised scattering has first recently been developed (Emde et al., 2004a). This development now allows cloud ice signatures in Odin-SMR tropospheric spectra to be quantified, and a first retrieval scheme is presented here. The atmospheric opacity sets a practical lower limit for Odin-SMR measurements to around $10 \mathrm{~km}$ and the retrieval is restricted to the upper tropical troposphere.

A second sub-mm limb sounder is now in space, Aura MLS launched in 2004. Cloud ice retrievals from this instrument have already been presented but then only using $\mathrm{mm}$ wave data, from $230 \mathrm{GHz}$ (Li et al., 2005; Wu et al., 2006). This instrument has also a $640 \mathrm{GHz}$ radiometer, while the Odin-SMR data used here are from 501 and $544 \mathrm{GHz}$. The both microwave limb sounders can give valuable data sets, to e.g. constrain climate models (Li et al., 2005) and to support the analysis of dedicated cloud missions, such as the CloudSat $94 \mathrm{GHz}$ cloud profiling radar (Stephens et al., 2002). This paper is the first step for Odin-SMR in this direction.

\section{The Odin satellite}

\subsection{Overview}

The Odin mission is a collaboration between Sweden, Canada, France and Finland, with the launch of the satellite in February 2001 (Nordh et al., 2003). The observation time is divided on equal terms between astronomy and atmospheric science objectives. The satellite carries two instruments, a sub-mm radiometer package (SMR) and an optical spectrograph and infrared imager system (OSIRIS). The SMR instrument is used for both astronomy and atmospheric observations, while OSIRIS is only operated during the atmospheric part (Murtagh et al., 2002).

The limb scanning of Odin is performed by rotating the complete satellite, with a rate giving a vertical movement of the tangent point of about $750 \mathrm{~m} / \mathrm{s}$. Spectra are taken during both downward and upward scanning, with the lower turning point at a nominal altitude of $5 \mathrm{~km}$. The integration time is $0.875 \mathrm{~s}$ and subsequent spectra are recorded every $2 \mathrm{~s}$. These values are changed to 1.875 and $4 \mathrm{~s}$, respectively, for shorter periods to avoid overflow of onboard memory capacity. The near polar orbit is sun-synchronous, with an altitude of about $600 \mathrm{~km}$ and ascending node around 18:00 $\mathrm{h}$ local time.

\subsection{The data}

This study is based solely on data from the SMR receiver (Frisk et al., 2003). The four front-ends of SMR give together sensitivity tunable over $486.1-503.9$ and $541.0-581.4 \mathrm{GHz}$, while spectrometer and data rate constraints set a limit at about $1.6 \mathrm{GHz}$ for the instantaneous overall bandwidth, and SMR is operated in several observation modes to cover all molecular transitions of interest. The data used here are taken from the most frequently used mode, the stratospheric mode, which aims at retrieving $\mathrm{ClO}, \mathrm{N}_{2} \mathrm{O}, \mathrm{HNO}_{3}$ and $\mathrm{O}_{3}$. The stratospheric mode consists of two bands, at 501 and $544 \mathrm{GHz}$. Relevant spectroscopic features of these bands are shown in Fig. 1. SMR is a single sideband receiver, with a maximum contribution from the image band of 5\%. The main and image bands are separated with $7.8 \mathrm{GHz}$. See Urban et al. (2005) for further details and a description of the standard processing.

The basic observation schedule gives stratosphere mode data every third day, but the data set is more dense during the December-May period due to observation campaigns focusing on Arctic winter polar research. For these first retrievals only spectra for tangent altitudes below $9 \mathrm{~km}$ are considered (Sect. 4.1). This means that used data are grouped around the scan turning points, where the groups consist of 3-10 
spectra. The closest horizontal distance between subsequent groups of spectra is $1000 \mathrm{~km}$. Example data values are found in Fig. 2.

The response of the SMR receivers is linearly polarised. The mounting is such that the response corresponds to $45^{\circ}$ polarisation in atmospheric coordinates (with $+45^{\circ}$ for two front-ends, and $-45^{\circ}$ for the other two front-ends). The consequences of this fact are discussed in Sect. 3.2.

\section{Radiative transfer}

\subsection{Software}

Radiative transfer simulations were performed with version 1.1 of the Atmospheric Radiative Transfer Simulator (ARTS). This is a development version of ARTS-1 (Buehler et al., 2005), where features needed for rigorous simulations of scattering in limb sounding geometry have been added. Polarisation effects are fully considered, where the polarisation state is expressed by the Stokes formalism. The geoid and the surface can have arbitrary shape, and atmospheric fields can have variations in all three dimensions. Scattering by molecules and aerosols can be neglected for sub-mm radiation, and this is reflected in ARTS-1.1 such that the scattering calculations can be restricted to a smaller part of the model atmosphere. Two modules for the treatment of scattering exist, a discrete ordinate iterative method (Emde et al., 2004a) and a reverse Monte Carlo algorithm (Davis et al., 2005a). Particle properties for single scattering are calculated externally, where the T-matrix code of Mishchenko and Travis (1998) was used for this study. Figure 1 shows that Odin-SMR spectra with evident cloud signatures (with scattering as the dominating effect, Sect. 3.3) can be recreated in detail by the simulations, a fact that gives high confidence in the performance of ARTS-1.1.

\subsection{Simulation set-up}

Spectroscopic data were taken from the retrieval of stratospheric gas species (Urban et al., 2005). Pure clear-sky calculations were performed in a 2-D mode, with temperatures and geometrical altitudes from ECMWF and gaseous vertical profiles from the SMR a priori climatology as described in Ekström et al. (2007). The vertical variation of the antenna response was considered for the clear-sky part, while this effect was ignored for scattering calculations, as tests showed that this allowed much more rapid calculations with negligible impact on final results. The contribution from the image sideband can be neglected, primarily as the relative contribution from the image band is low. The importance of modelling the image band contribution is further decreased by the facts that both sidebands exhibit very similar radiances for considered range of tangent altitudes, and the strength of scattering differs only marginally between the bands.

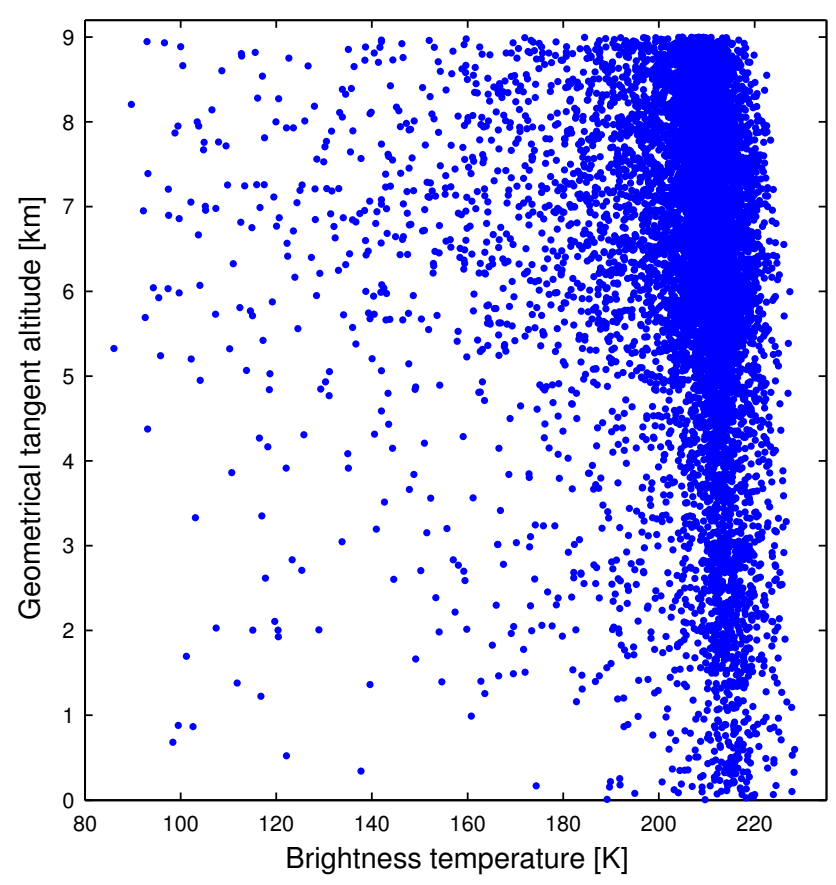

Fig. 2. Randomly selected values (10000) from the $501 \mathrm{GHz}$ part of the data set (mean over $501.2-501.3 \mathrm{GHz}$, all data from tropical latitudes). The band of data values around $210 \mathrm{~K}$ corresponds to clear-sky conditions and relatively thin clouds, while lower brightness temperatures can only be caused by more dense ice clouds.

ARTS allows that the atmospheric fields vary in all three dimensions, but a spherically symmetric atmosphere (1-D) was assumed when determining the cloud induced change in brightness temperature. The main reason for this simplification was the lack of relevant 3-D cloud fields to be used as input. A compensation term for the neglection of the horizontal variation in the cloud fields is discussed in Sect. 4.5.

The calculations were performed by the method of Emde et al. (2004a), but some Monte Carlo simulations were also made for validation purposes. Different shapes of the ice particles were considered, as described in Sect. 4.3. The particle orientation was assumed to be either completely random or azimuthally random. No $\pm 45^{\circ}$ or circular polarisation (Stokes components 3 and 4) are generated for these conditions and it is sufficient to only consider the first two Stokes components in the simulations. This theoretically based statement was confirmed by simulations. A consequence of this fact is that the signal recorded by SMR correspond to the mean of the intensity for vertical and horizontal polarisation, here equal to the first Stokes element, as long as no esoteric particle orientation occurs in the atmosphere. 


\subsection{Cloud impact}

Compared to the corresponding clear-sky case, cloud ice extinction can cause both increased and decreased radiances in $\mathrm{mm}$ and sub-mm limb sounding measurements. The sign of the effect depends on the vertical variation of gaseous absorption, cloud altitude and tangent altitude (see Emde et al., 2004b, for simulation results and Wu et al., 2005, for observation evidence). Increased radiances are primarily found where both cloud top and tangent altitudes are high, while for the measurement geometry used here cloud extinction gives decreased brightness temperatures throughout, as already indicated in Figs. 1-2.

Cloud ice extinction consists of two parts, absorption and scattering. Absorption dominates for particles smaller than $\sim 50 \mu \mathrm{m}$, while scattering is the main extinction mechanism for larger particles. The overall division between absorption and scattering depends accordingly on the PSD. Test calculations for various conditions relevant to these Odin-SMR cloud retrievals showed that scattering is the leading term $(>80 \%)$.

The observation geometry further emphasises the scattering effects over those of particle absorption. Both absorption and scattering have corresponding source terms, i.e. emission and scattering into the line-of-sight, respectively. The attenuated radiation originates from altitudes just below the cloud layer, thus having a brightness temperature close to the physical temperature inside the cloud. This has the consequence that the difference in brightness temperature of absorbed and emitted radiation is relatively small (difference $<25 \mathrm{~K}$ ). Particle absorption alone can thus only generate brightness temperatures relatively close to corresponding clear-sky radiance. For example, the values in Figs. $1-2$ below $\approx 180 \mathrm{~K}$ can only be explained by scattering. The existence of values down to $100 \mathrm{~K}$ therefore illustrates the efficiency of scattering effects on measured $T_{b}$.

\section{Retrieval algorithm}

\subsection{Basic considerations and approach}

As mentioned, this initial Odin-SMR cloud ice retrieval scheme uses only spectra with tangent altitudes below $9 \mathrm{~km}$. There are several reasons to start with this part of the data set. First of all, the clearest cloud signatures are found for these tangent altitudes (up to $120 \mathrm{~K}$, see Fig. 2). The effect of cloud extinction is consistently a decrease in measured intensities (Sect. 3.3), a fact that simplifies the analysis considerably. Further, Ekström et al. (2007) show that at these tangent altitudes radiance spectra depend primarily on a small set of atmospheric variables (temperature, humidity and cloud extinction), and that uncertainties around sideband filtering and antenna response can be neglected.
Odin-SMR is a limb sounder, but the measurement methodology applied here has more the character of downlooking geometry. This is the case as high absorption below $9 \mathrm{~km}$ removes all influence of the most distant part of the limb view. The region around the tangent point acts practically as a blackbody. This yields many similarities with the dedicated sub-mm cloud ice measurements proposed in Evans et al. (2002), using the lower part of the troposphere as a blackbody background. There are though some important differences. The high incidence angles of Odin-SMR give sensitivity to only higher altitudes, and the mean particle size can not be determined as the two channels used (501 and $544 \mathrm{GHz}$ ) are too close in wavelength to provide useful information.

The measurement principle is then as follows. The measured emission intensity is, for clear-sky conditions, governed by temperature and humidity. Clouds along the lineof-sight at sufficient altitude (above $\approx 11 \mathrm{~km}$ for $501 \mathrm{GHz}$ and $\approx 13 \mathrm{~km}$ for $544 \mathrm{GHz}$ ) will result in a decrease in the observed brightness temperature, $\mathrm{T}_{\mathrm{b}}$. The first step of the retrieval is to determine the cloud induced $\mathrm{T}_{\mathrm{b}}$ depression, and the second step is to map the depression to a cloud ice amount. The unknown vertical extension of the cloud causes a retrieval ambiguity that can be partly handled by combining information from 501 and $544 \mathrm{GHz}$. Each pair of $501 / 544 \mathrm{GHz}$ spectra is treated individually and each cloud retrieval represents a horizontal area $\sim 3 \mathrm{~km}$ wide in westeast direction, and $\sim 100 \mathrm{~km}$ long in north-south direction.

\subsection{Determination of cloud signal}

The cloud signal is defined as the $T_{b}$ depression compared to corresponding clear-sky case, here designated $\Delta \mathrm{T}_{\mathrm{b}}$. The determination of clear-sky radiance is based on the parallel humidity retrieval, described in the accompanying paper by Ekström et al. (2007). In short, Odin-SMR spectra are generated for different assumed relative humidities, and this set of simulations are used to map the measured $T_{b}$ value to a humidity. The simulations are performed in a 2-D mode and full account of horizontal gradients in atmospheric temperatures (from ECMWF) is taken. A detailed investigation made it possible to compensate for a small systematic calibration error, but also revealed a $\sim 2 \mathrm{~K}$ random component that is directly translated to an identical uncertainty in $\Delta \mathrm{T}_{\mathrm{b}}$.

The $T_{b}$ depression is taken as the difference between measured $\mathrm{T}_{\mathrm{b}}$ and simulated value for $120 \% \mathrm{RHi}$. It could be argued that $100 \%$ RHi or the humidity retrieved in Ekström et al. (2007) are better choices for the reference level, but this question has little practical concern. The corresponding $\Delta \mathrm{T}_{\mathrm{b}}$ uncertainty is $\sim 1 \mathrm{~K}$. The level $120 \% \mathrm{RHi}$ was selected to obtain a more conservative estimate of the cloud detection frequency. 


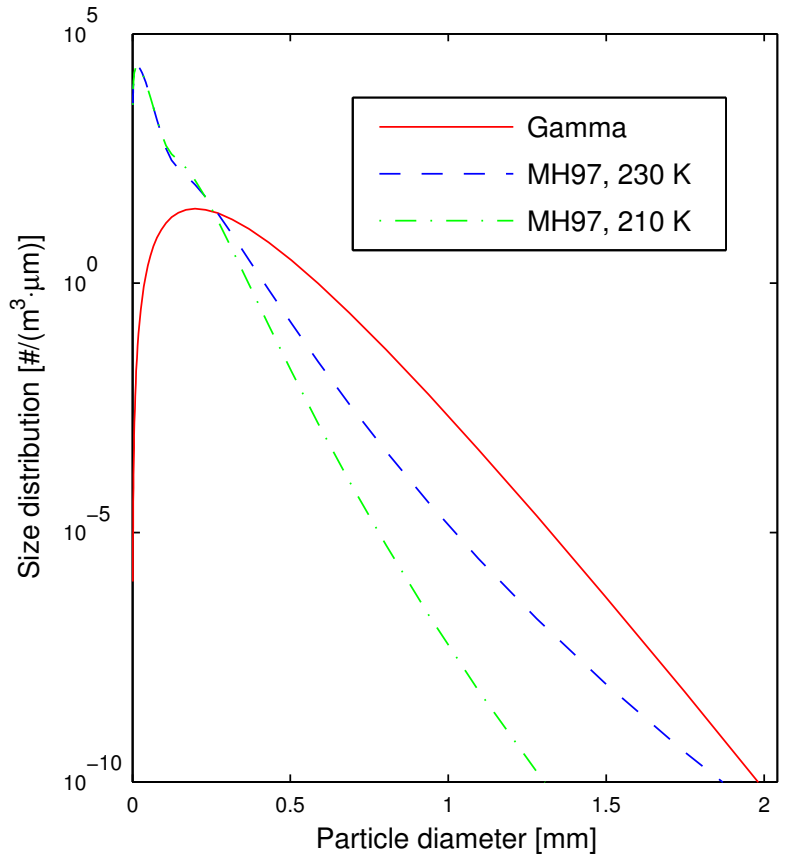

Fig. 3. Particle size distributions for an ice water content of $0.1 \mathrm{~g} / \mathrm{m}^{3}$. The parameterisation of McFarquhar and Heymsfield (1997), MH97, is shown for two temperatures. The gamma distribution is the one used for retrieval of minimum cloud ice columns.

\subsection{Impact of microphysical parameters}

As a consequence of the frequencies available the measurements can not be used to confine the mean particle size and thus a particle size distribution (PSD) must be assumed. The PSD of McFarquhar and Heymsfield (1997) (hereafter MH97) is commonly used for tropical conditions and it is also used here as best estimate of the mean tropical PSD.

The uncertainty in the local PSD maps to a retrieval error, discussed further in Sect. 5.2. A related issue is that it is difficult to give an upper limit on cloud ice amount with OdinSMR, mainly due to the low sensitivity to ice bound in small particles (Sect. 3.3). On the other hand, a firm lower limit on cloud ice amount can be determined by assuming that the particle size is such that maximum impact is obtained. A mono-dispersive PSD would be an extreme assumption and a narrow gamma distribution was instead selected. The width parameter was set to 4 , to obtain the most narrow PSD that is consistent with values reported by Heymsfield (2003). Simulations showed that a PSD peaking at $\sim 200 \mu \mathrm{m}$ fulfils the criterion for estimating the minimum value. The MH97 and gamma PSDs are compared in Fig. 3. The importance of assuming a given PSD on the mapping between $\Delta \mathrm{T}_{\mathrm{b}}$ and cloud ice amounts is shown in Fig. 4.

The influence of particle shape was studied by considering different spheroidal shapes, with aspect ratios between

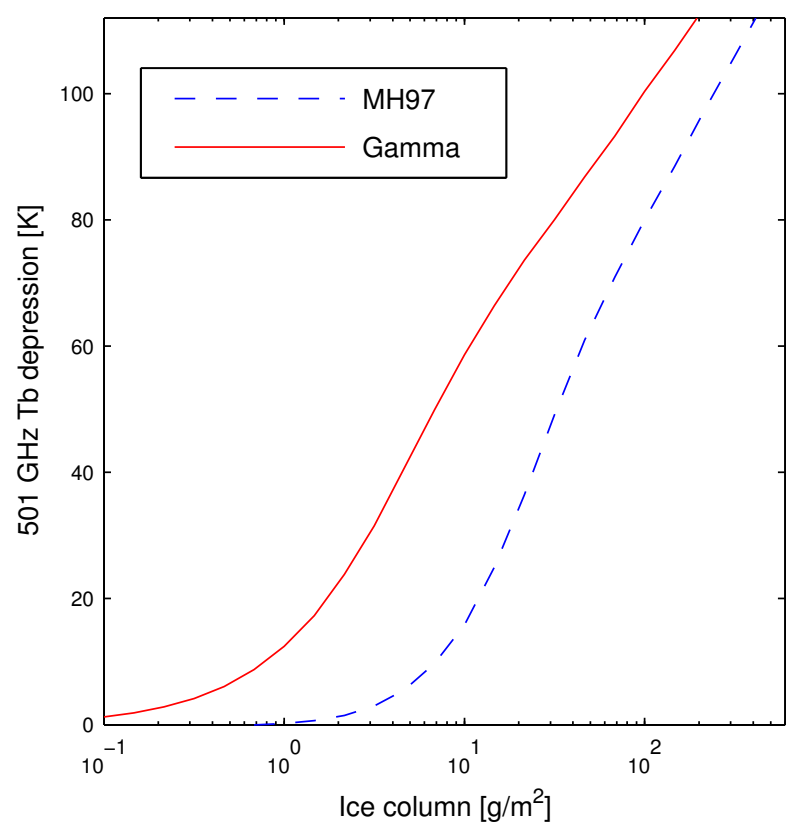

Fig. 4. The relationship between $T_{b}$ depression and cloud ice amount for two different particle size distributions. Simulations are for $501 \mathrm{GHz}, 7 \mathrm{~km}$ tangent altitude and cloud ice between 12 and $14 \mathrm{~km}$.

1 and 3.5. An aspect ratio $>1$ means that the horizontal length exceeds the vertical extent. ARTS (Sect. 3.1) allows two options for particle orientation, randomly oriented and horizontally aligned. The later option implies random azimuthal orientation. Results for different combinations of aspect ratio and particle orientation are shown in Fig. 5. For an aspect ratio of 1 there is no difference between the two orientation options. No significant variation was found for different aspect ratios as long as randomly oriented particles are assumed. A polarisation dependent impact of aspect ratio is though found for horizontally aligned particles. The polarisation dependency is shown in Fig. 5 for an aspect ratio of 3.5. Odin-SMR corresponds to the dashed curve (mean of $\mathrm{I}_{v}$ and $\mathrm{I}_{h}$, see Sects. 2.2 and 3.2), which in this context is the most advantageous case as the mapping between $\Delta \mathrm{T}_{\mathrm{b}}$ and ice amount is more affected by the aspect ratio for vertical and horizontal polarisation.

However, an aspect ratio value of 3.5 was included mainly for illustration, and values of 1-2 should be more representative for atmospheric conditions as the overall ensemble aspect ratio should not in general deviate strongly from 1 (A.J. Heymsfield, private communication). A mean aspect ratio of 1.2 was also found in an investigation of $122 \mathrm{GHz}$ MLS data (Davis et al., 2005b). Our conclusion is thus that incorrect assumptions on particle shape and orientation should only cause marginal retrieval errors. Spherical particles will be assumed in the remainder of this paper. 


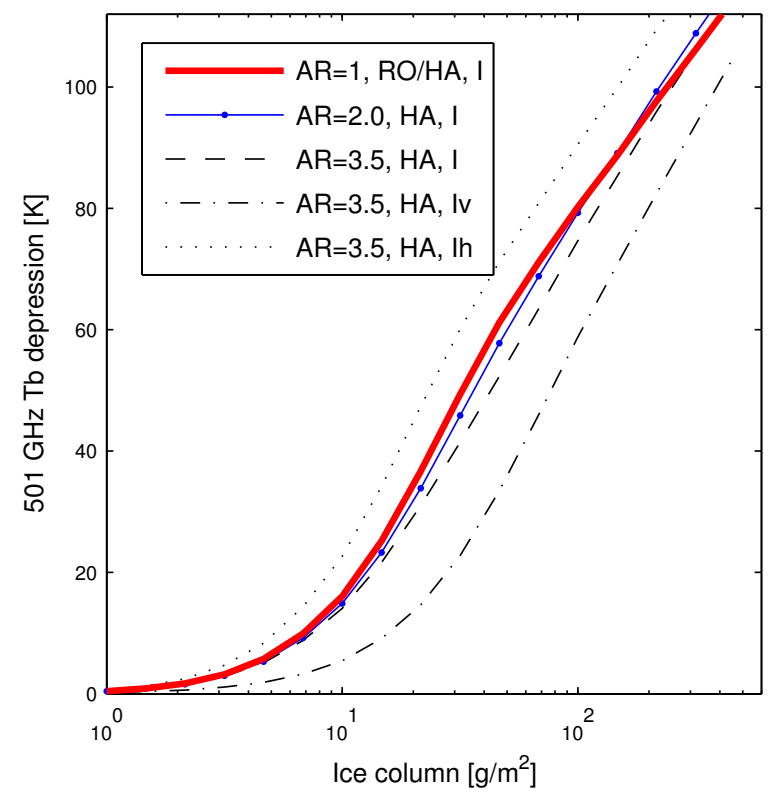

Fig. 5. The relationship between $501 \mathrm{GHz} \mathrm{T}_{\mathrm{b}}$ depression and cloud ice amount for different assumptions on particle shape and orientation where: $\mathrm{AR}=$ aspect ratio, $\mathrm{RO}=$ randomly oriented, $\mathrm{HA}=$ horizontally aligned, $\mathrm{I}=$ mean of $\mathrm{I}_{v}$ and $I_{h}$, and $\mathrm{I}_{v / h}=$ intensity at vertical and horizontal polarisation, respectively. Simulations for MH97 PSD and cloud ice between 12 and $14 \mathrm{~km}$.

\subsection{Impact of cloud thickness and altitude}

The $\mathrm{T}_{\mathrm{b}}$ depression caused by a given ice amount depends on the cloud altitude. The altitude variation is mainly governed by the absorption properties at the frequency considered, and thus differs between the 501 and $544 \mathrm{GHz}$ bands. The general principle is that a high cloud, where the gaseous absorption is smaller, gives a higher $\Delta \mathrm{T}_{\mathrm{b}}$ for a given ice amount. This is illustrated in Fig. 6 for $501 \mathrm{GHz}$. The ice is, here and elsewhere in the study assumed to be, evenly distributed in the cloud layer. The gamma PSD is used for this comparison to avoid that the PSD changes with altitude (through the temperature dependency of MH97).

The $501 \mathrm{GHz}$ band has low absorption above $\sim 14 \mathrm{~km}$ and accordingly the mapping is relatively constant for cloud altitudes above this altitude, while a large difference is seen in comparison to an altitude of e.g. $12 \mathrm{~km}$. The absorption in the $544 \mathrm{GHz}$ band extends to higher altitudes and the cloud altitude influences the mapping up to $\sim 16 \mathrm{~km}$.

The altitude variation of the cloud influence means that the cloud thickness can not be neglected. However, by introducing an adaptive definition of the cloud altitude this issue can be made less problematic. Simulations showed that for thin clouds the impact of cloud thickness is small if the centre point of the cloud layer is kept constant. The same is achieved for thick clouds if the top altitude is considered instead. These features are illustrated by the $13 / 3 \mathrm{~km}$ case

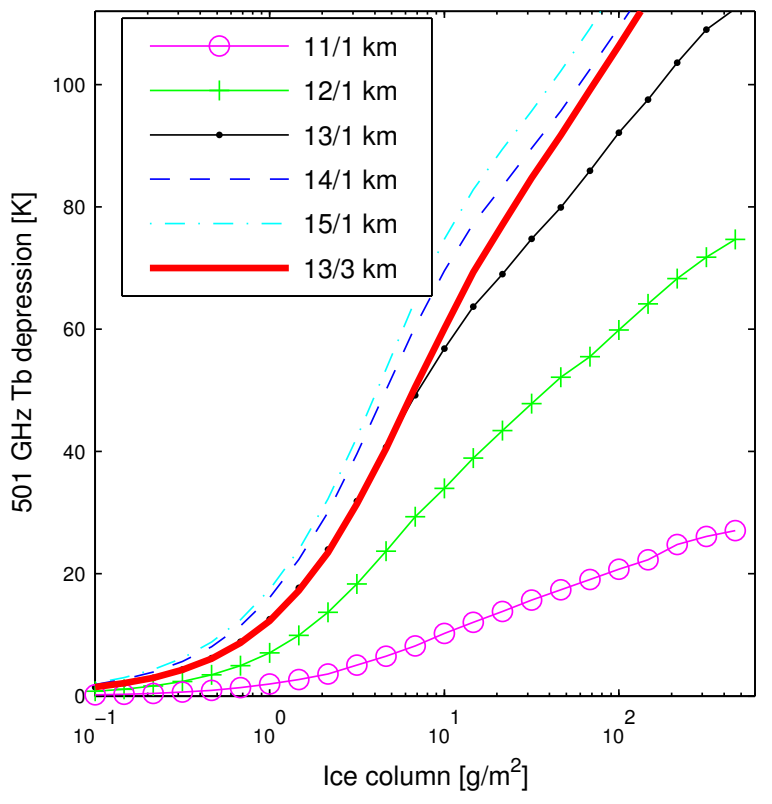

Fig. 6. The relationship between $501 \mathrm{GHz} \mathrm{T}_{\mathrm{b}}$ depression and cloud ice amount for different cloud altitudes and layer thicknesses. For example, the dotted line is for a cloud centre altitude of $13 \mathrm{~km}$ and a $1 \mathrm{~km}$ thick cloud layer. Simulations are for $7 \mathrm{~km}$ tangent altitude and the $200 \mu \mathrm{m}$ gamma distribution.

in Fig. 6, that follows closely $13 / 1 \mathrm{~km}$ for weak clouds and asymptotically approaches $14 / 1 \mathrm{~km}$ for strong clouds. That is, the term cloud altitude will be defined as the centre point for clouds with low ice amounts, and gradually move towards the top altitude for increasing ice columns. The effective altitude for the highest cloud columns encountered here should be $100-200 \mathrm{~m}$ below the cloud top altitude. The definition of the cloud top must though be taken as the highest altitude with particles large enough to influence sub-mm radiation, that probably can differ substantially from the optically determined cloud top.

\subsection{Inhomogeneity correction}

The mapping functions between $\Delta \mathrm{T}_{\mathrm{b}}$ and cloud mass are calculated for a spherically symmetric atmosphere (1-D, Sect. 3.2). This corresponds to a situation when the cloud ice is evenly distributed horizontally, while Davis et al. (2006) have shown that for realistic 3-D distributions deviating results are obtained. The 3-D case gives lower $\Delta \mathrm{T}_{\mathrm{b}}$ values for down-looking observation geometries, such as considered here. This difference between 1-D and 3-D originates mainly in the non-linear relationship between cloud ice mass and $\Delta \mathrm{T}_{\mathrm{b}}$ (Figs. 4-6). The non-linearity has the consequence, for example, that the highest $\Delta \mathrm{T}_{\mathrm{b}}$ for a given (antenna response weighted) cloud ice mass is obtained if the ice is evenly distributed over the footprint, which corresponds to the 1-D situation. 
It should be possible to partly compensate for the neglected cloud inhomogeneity, as the difference between 1-D and 3-D is throughout positive. Davis et al. (2006) present a case study of differences between 1-D and 3-D simulations, and in lack of more general data, relevant results (downlooking type, aspect ratio $=1.3$ ) in Davis et al. (2006) are here used as a basis for rough correction. Those results show a low relative difference for small values of $\Delta T_{b}$, which is also expected as the non-linearity discussed above is most pronounced for higher ice columns. The 1-D- $\Delta \mathrm{T}_{\mathrm{b}}$ is $10-$ $40 \%$ above the corresponding 3-D value for cases with higher cloud extinction (1-D- $\Delta \mathrm{T}_{\mathrm{b}}$ between 20 and $50 \mathrm{~K}$ ). It can further be noted that Figs. 4-6 indicate a relatively constant degree of non-linearity for 1-D- $\Delta \mathrm{T}_{\mathrm{b}}>20 \mathrm{~K}$. If $20 \%$ is taken as a conservative estimate of the 1-D/3-D difference for thicker clouds, a simple scheme to correct calculated $1-\mathrm{D}-\Delta \mathrm{T}_{\mathrm{b}}$ values is

$$
\Delta \mathrm{T}_{\mathrm{b}}^{\prime}=c \Delta \mathrm{T}_{\mathrm{b}}, \quad c=\max \left\{0.8,1-\Delta \mathrm{T}_{\mathrm{b}} / 100\right\} .
$$

\subsection{Mapping to partial ice column}

The band at $501 \mathrm{GHz}$ is sensitive to clouds down to $\sim 11 \mathrm{~km}$ (Fig. 6), while for $544 \mathrm{GHz}$ the sensitivity starts at $\sim 14 \mathrm{~km}$ (not shown). The higher absorption at $544 \mathrm{GHz}$ implies that for all realistic cases the $\Delta \mathrm{T}_{\mathrm{b}}$ will be higher for $501 \mathrm{GHz}$ than for $544 \mathrm{GHz}$, despite a higher scattering cross-section at the higher frequency $(60 \%$ if Rayleigh scattering is assumed). The $501 \mathrm{GHz}$ band becomes then the primary band for cloud detection and retrievals.

However, the retrieval can not be based on $501 \mathrm{GHz}$ solely as the unknown cloud altitude would then cause a very high retrieval error. For example, a $501 \mathrm{GHz} \Delta \mathrm{T}_{\mathrm{b}}$ of $20 \mathrm{~K}$ can either be a $\sim 200 \mathrm{~g} / \mathrm{m}^{2}$ cloud at $11 \mathrm{~km}$ or a $\sim 1 \mathrm{~g} / \mathrm{m}^{2}$ cloud at $15 \mathrm{~km}$ (Fig. 6). By incorporating $544 \mathrm{GHz}$ data this ambiguity can be decreased greatly. In simple terms, if no $T_{b}$ depression is found for $544 \mathrm{GHz}$ the cloud altitude is below $14 \mathrm{~km}$, and vice versa. For clouds above $14 \mathrm{~km}$ the relative size in $\Delta \mathrm{T}_{\mathrm{b}}$ at 501 and $544 \mathrm{GHz}$ enables a relatively accurate determination of the cloud altitude.

The retrieval scheme is described more in detail by Fig. 7. The figure confirms the discussion above. For example, it shows that altitude ambiguity can be handled above $14 \mathrm{~km}$ by combining information from 501 and $544 \mathrm{GHz}$. The ice amount in clouds at lower altitudes is retrieved assuming a cloud altitude between 13.5 and $14 \mathrm{~km}$. The $544 \mathrm{GHz} \Delta \mathrm{T}_{\mathrm{b}}$ is used as an indicative weighting between 13.5 and $14 \mathrm{~km}$. If the real cloud altitude is lower, this gives an underestimation of the cloud ice. This behaviour corresponds to a lower retrieval response to ice below $14 \mathrm{~km}$. The retrieval has thus an altitude dependent response, which is estimated in Fig. 8. The altitude response was obtained by comparing ice-depression mapping curves for different cloud altitudes (Fig. 6), evaluated for a $501 \mathrm{GHz} \Delta \mathrm{T}_{\mathrm{b}}$ of $50 \mathrm{~K}$. This estimate should represent average conditions, but it shall be noted that the altitude response is not a constant quantity. A higher $\Delta \mathrm{T}_{\mathrm{b}}$ value corresponds to a lower response to cloud ice at lower altitudes. This simply as very high $\Delta \mathrm{T}_{\mathrm{b}}$ values can not be obtained with cloud altitudes around e.g. $11 \mathrm{~km}$.

This Odin-SMR cloud ice retrieval is thus an estimate of a partial cloud ice column, with an altitude response given by Fig. 8. This means that a vertical IWC profile, $\boldsymbol{x}$ is converted to "Odin-SMR ice column", $\overline{\boldsymbol{x}}$, as

$\overline{\boldsymbol{x}}=\int_{z} \mathbf{A}(z) \boldsymbol{x}(z) d z$

where $\mathbf{A}$ is the function depicted in Fig. 8, and $z$ is vertical coordinate. The response of 0.5 is found at $\sim 12.5 \mathrm{~km}$ and this altitude is used when a lower altitude for the column value must be specified. Figures 4-8 are all valid for a tangent altitude of $7 \mathrm{~km}$. Mappings and response are very similar for other considered tangent altitudes.

The highest Odin-SMR $501 \Delta \mathrm{T}_{\mathrm{b}}$ values are about $120 \mathrm{~K}$ (Figs. 2-7), corresponding to $\sim 500 \mathrm{~g} / \mathrm{m}^{2}$. This does not correspond to a physical limit on $\Delta \mathrm{T}_{\mathrm{b}}$, neither is there any clustering of measurement data at the upper range of $\Delta \mathrm{T}_{\mathrm{b}}$ values, which indicates that the saturation level of the cloud ice retrieval has not been reached.

\section{Results}

The main objective of the paper is to present the retrieval methodology and only example results are given, to indicate the quality and potential usage of the Odin-SMR data set. More detailed investigations are left for forthcoming publications. Mean results for the December 2001-August 2004 period are shown, following Ekström et al. (2007).

\subsection{Cloud detection frequency}

A cloud is considered as detected if the $501 \mathrm{GHz} \Delta \mathrm{T}_{\mathrm{b}}$ exceeds some specified value. The threshold value should be as small as possible while avoiding a significant number of false cloud detections due to uncertainties in the estimated $\Delta \mathrm{T}_{\mathrm{b}}$. The main $\Delta T_{b}$ uncertainty is the random calibration error discussed in Sect. 4.2. For example, the data points in Fig. 7 above the $16 \mathrm{~km}$ curve (with low depression values for both bands) are primarily an effect of the random calibration error, and shall not be taken as detections of high altitude clouds. The $501 \mathrm{GHz}$ random calibration error was estimated to $2 \mathrm{~K}$, and considering this uncertainty, $5 \mathrm{~K}$ is used as threshold for the cloud detection frequency. This threshold value corresponds to an ice column of about $4 \mathrm{~g} / \mathrm{m}^{2}$ (Fig. 7). Such an ice water path has an optical zenith opacity in the order of 0.2 (Heymsfield et al., 2003).

The cloud detection frequency for the time period considered is shown in Fig. 9. Somewhat higher cloud frequencies are obtained for lower $\Delta \mathrm{T}_{\mathrm{b}}$ threshold values, but the geographical pattern is not changed. The mean difference 


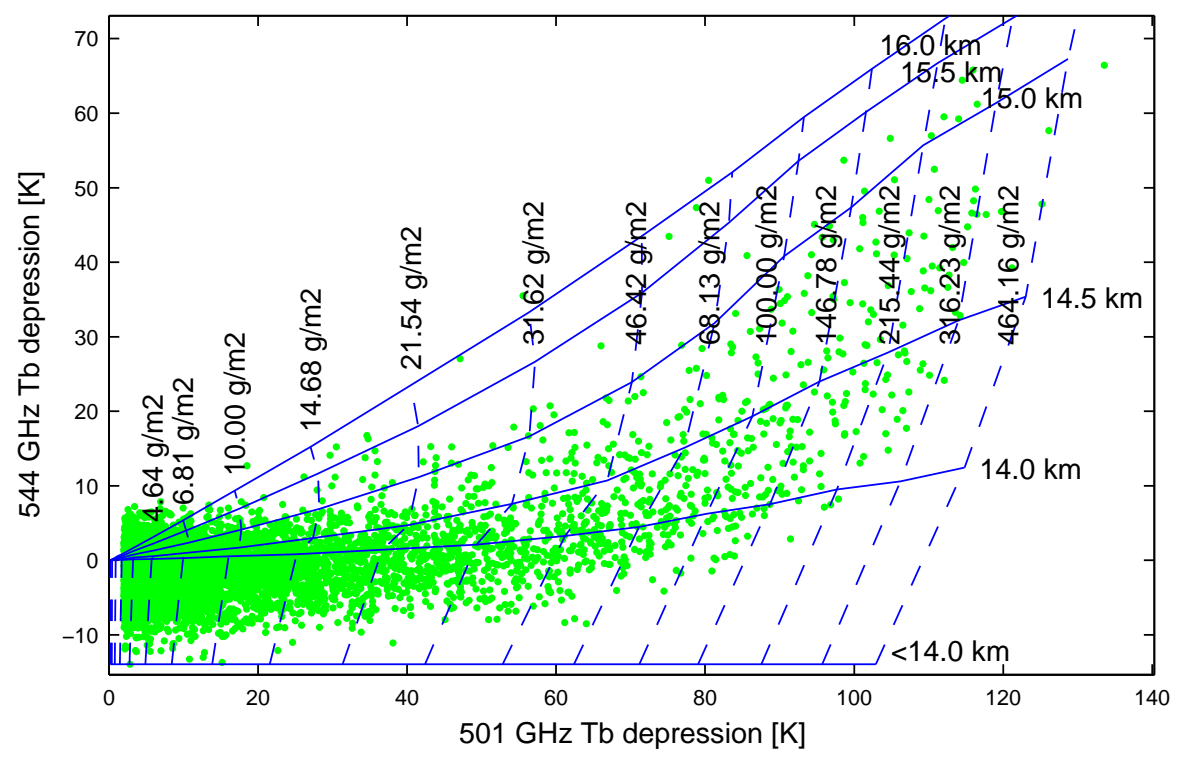

Fig. 7. Schematic of the retrieval algorithm. Dots (green) are measured values, given as estimated cloud ice induced brightness temperature depression at 501 and $544 \mathrm{GHz}$. Solid lines are the relationship between 501 and $544 \mathrm{GHz}$ depressions found in simulations for constant cloud altitudes. Dashed lines show same relationship but for constant values of the cloud ice column. Clouds below about $14 \mathrm{~km}$ can not be altitude determined (see further Sect. 4.6). The MH97 PSD and a cloud layer thickness of $2 \mathrm{~km}$ are assumed. Data points with an apparent altitude above $16 \mathrm{~km}$ are discussed in Sect. 5.1 .

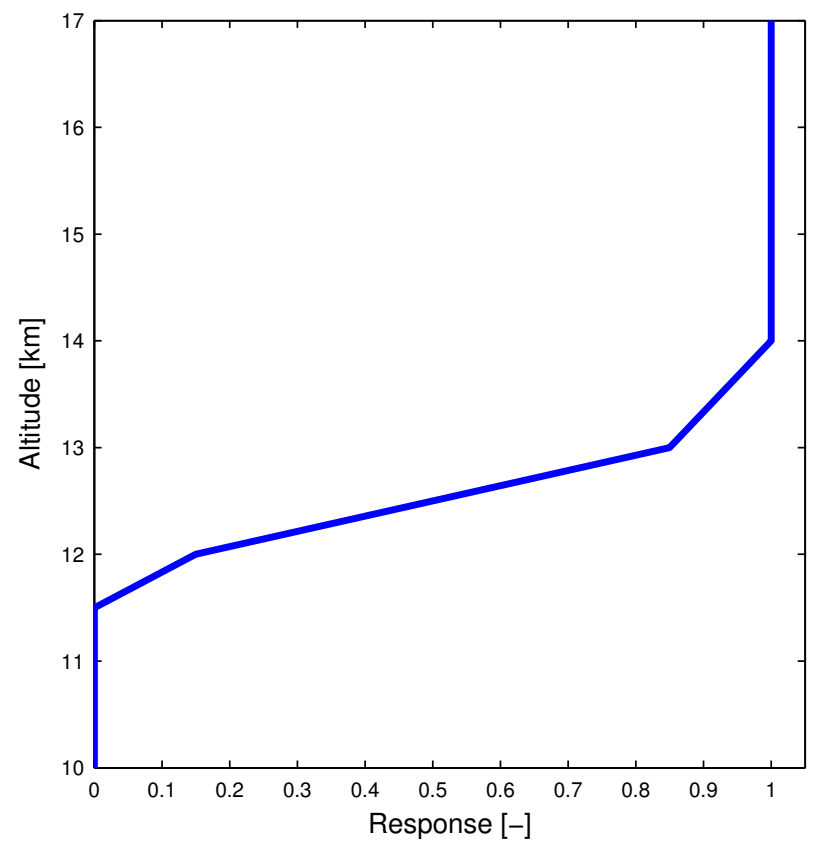

Fig. 8. Estimated altitude variation of cloud ice retrieval response. Data from other sources should be weighted with this response before being compared to Odin-SMR results obtained by the retrieval algorithm described here. between a threshold of 2 and $5 \mathrm{~K}$ was determined to be 0.03 , and this can be taken as a general error estimate for Fig. 9.

The fact that the cloud detection frequency is close to zero over substantial areas, at expected geographical positions, is a strong confirmation of the claim that the $501 \mathrm{GHz} \Delta \mathrm{T}_{\mathrm{b}}$ is determined to a precision of $\sim 2 \mathrm{~K}$.

\subsection{Partial cloud ice columns}

The 501 and $544 \mathrm{GHz} \Delta \mathrm{T}_{\mathrm{b}}$ values are mapped to partial cloud ice columns in the manner described in Sect. 4.6. The cloud ice column is normally denoted as the ice water path (IWP). All measurements with $501 \mathrm{GHz} \Delta \mathrm{T}_{\mathrm{b}}$ below $2 \mathrm{~K}$ are treated as cloud free. An estimate of minimum IWP is obtained by assuming a $200 \mu \mathrm{m}$ gamma PSD (Sect. 4.3) and using 1-D mapping values without any correction, while best estimate of IWP is found by applying the correction in Eq. (1) and assuming the MH97 PSD.

Mean IWP fields for the time period considered are shown in Fig. 10, together with data from atmospheric models for comparison. ECMWF is a model for numerical weather prediction and assimilates both satellite and in-situ measurements, while ECHAM is a pure climate model (GCM) and ice field shown does not represent a particular time period.

The relative difference between minimum and best estimates decreases with increasing IWP (Fig. 3). The minimum IWP fields in Fig. 10 is a factor 4-8 lower than corresponding best estimates, for areas with mean IWP $>2.5 \mathrm{~g} / \mathrm{m}^{2}$. The difference in assumed PSD and 1-D/3-D correction contribute 


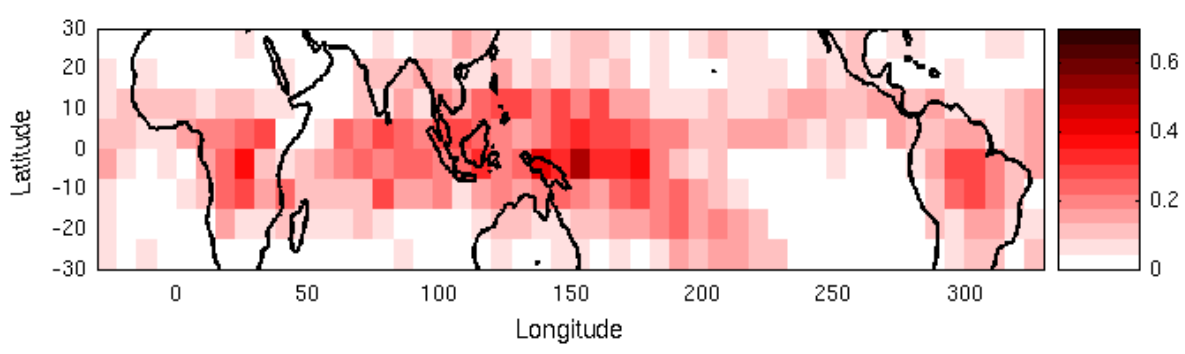

Fig. 9. Detection frequency for ice clouds above $\sim 12 \mathrm{~km}$, with a $5 \mathrm{~K}$ threshold for the $501 \mathrm{GHz} \Delta \mathrm{T}_{\mathrm{b}}$. The data cover December 2001 to August 2004, with a somewhat uneven distribution between seasons. No distinction has been made between ascending and descending passages.
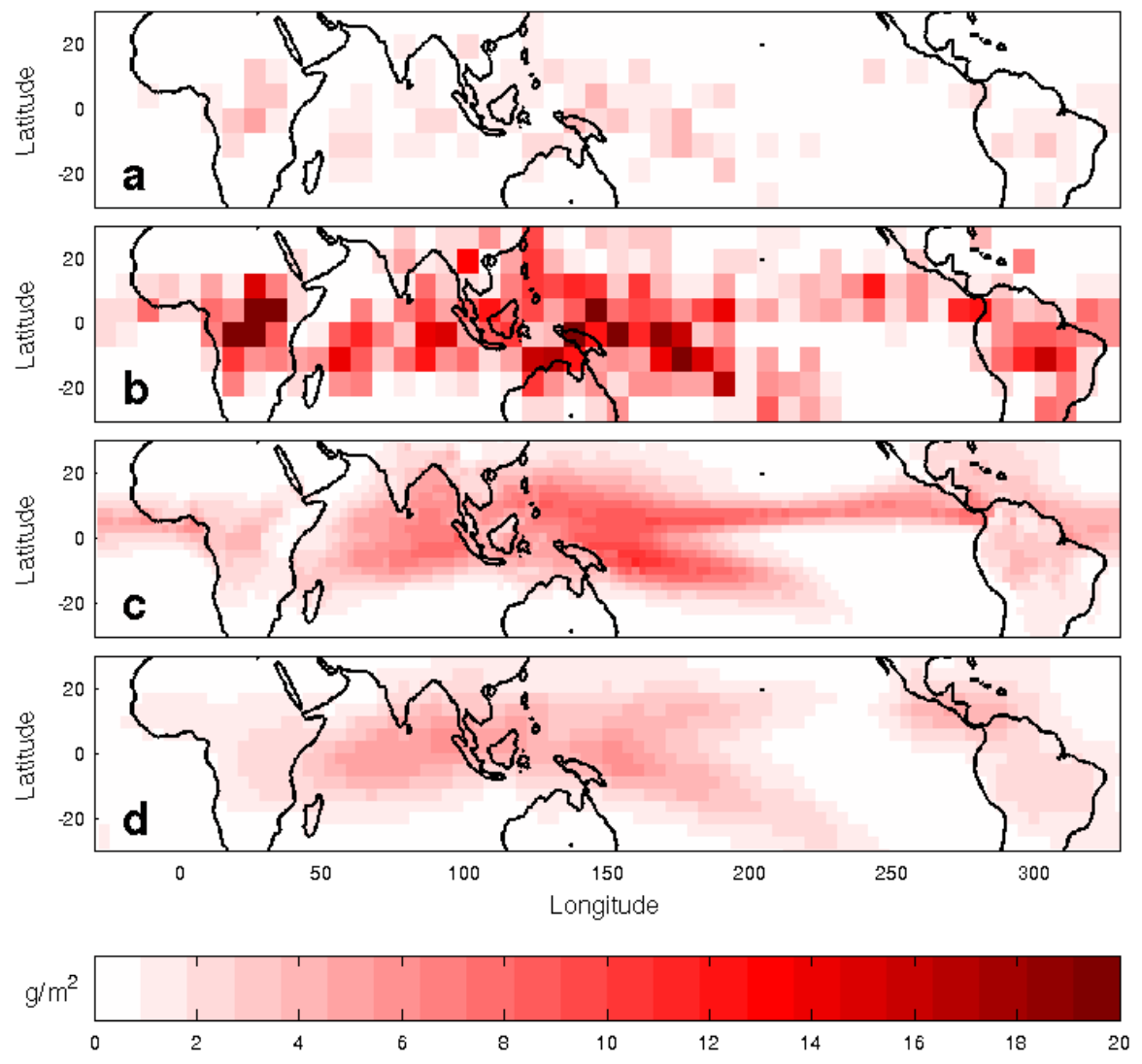

Fig. 10. Fields of partial ice columns: (a) Minimum Odin-SMR estimate (200 $\mu$ gamma PSD). (b) Best Odin-SMR estimate (MH97 PSD + 1-D/3-D correction). (c) ECMWF, 2002-2004 mean. (d) ECHAM, 5 year climatological mean. Odin-SMR retrievals are averaged over December 2001-August 2004. ECMWF and ECHAM fields are weighted following Eq. (2).

roughly equally to the deviation between minimum and best estimate. Both the $200 \mu \mathrm{m}$ gamma PSD and 1-D conditions have a low probability of occurrence in practise and true IWP values should accordingly be considerable higher than the minimum estimates. Despite this, the minimum estimates are found to be larger than the ECHAM results, and be similar to ECMWF, above central Africa. The minimum estimates are also of the same magnitude as the model data over S. America. Odin-SMR best estimates are also significantly above the

www.atmos-chem-phys.net/7/471/2007/
ECMWF and ECHAM for these regions. It should be noted that Odin-SMR does not sample the full diurnal cycle (tropical latitudes are passed at around 06:00 and 18:00 local time) and this effect has not been considered in the comparison to ECMWF and ECHAM.

The Odin-SMR and atmospheric model results show better agreement over the oceans, though with a higher mean value in the satellite data set but with similar geographical patterns. Odin-SMR tends to place the highest IWP values in more 
Table 1. Estimates of IWP retrieval errors. All estimates are given at the 1 standard deviation level. The error for cloud inhomogeneity assumes that a 1-D/3-D correction has been applied (Eq. 1). The basic estimate for error sources with $\Delta \mathrm{T}_{\mathrm{b}}$ stated is taken from Ekström et al. (2007), while the magnitude of other errors is discussed in Sect. 5.2.

\begin{tabular}{lccc}
\hline Error source & $\Delta$ & $\Delta \mathrm{T}_{\mathrm{b}}$ & $\Delta \mathrm{ice}$ \\
\hline Systematic errors & & & \\
\hline Cloud inhomogeneity & - & - & $30 \%$ \\
$\mathrm{PSD}$ & - & - & $30 \%$ \\
Microphysics & - & - & $15 \%$ \\
$557 \mathrm{GHz} \mathrm{H}_{2} \mathrm{O} i_{0}$ & $2 \%$ & $0.1 \mathrm{~K}$ & $0.3 \%$ \\
$557 \mathrm{GHz} \mathrm{H}_{2} \mathrm{O} a_{\gamma}$ & $8 \%$ & $0.4 \mathrm{~K}$ & $1.4 \%$ \\
$\mathrm{H}_{2} \mathrm{O}$ continua & $30 \%$ & $0.2 \mathrm{~K}$ & $0.7 \%$ \\
$\mathrm{~N}_{2}$ absorption & $30 \%$ & $0.5 \mathrm{~K}$ & $1.7 \%$ \\
Calibration, $\mathrm{T}_{\mathrm{b}}$ & $0.2 \mathrm{~K}$ & $0.2 \mathrm{~K}$ & $0.7 \%$ \\
Temperature & $1 \mathrm{~K}$ & $0.4 \mathrm{~K}$ & $1.4 \%$ \\
\hline Random errors & & & \\
\hline Cloud inhomogeneity & - & - & $40 \%$ \\
PSD & - & - & $40 \%$ \\
Microphysics & - & - & $15 \%$ \\
Thermal noise, $\mathrm{T}_{\mathrm{b}}$ & $0.5 \mathrm{~K}$ & $0.5 \mathrm{~K}$ & $1.7 \%$ \\
Calibration, $\mathrm{T}_{\mathrm{b}}$ & $2 \mathrm{~K}$ & $2 \mathrm{~K}$ & $7.2 \%$ \\
Pointing & $0.011^{\circ}$ & $0.4 \mathrm{~K}$ & $1.4 \%$ \\
Temperature & $1 \mathrm{~K}$ & $0.4 \mathrm{~K}$ & $1.4 \%$ \\
\hline Retrieval accuracy & & & $75 \%$ \\
\hline
\end{tabular}

localised areas, but this can be an effect of the limited size of the Odin-SMR data set.

Li et al. (2005) presented a comparison between Aura MLS cloud ice retrievals, ECMWF and a number of global climate models (ECHAM not included). The MLS retrievals are based on the MH97 PSD, without the 1-D/3-D correction suggested here. The MLS data and Odin-SMR results for the same retrieval conditions (not shown) appear to agree well, using ECMWF as a reference for the comparison. For example, notable differences between retrieved and model data above Africa and S. America were also found by Li et al. (2005). However, PSD and cloud inhomogeneities are main error sources for both MLS and SMR, and the results from both instruments are likely to have similar systematic errors. A closer comparison to Aura MLS is left for future work.

Table 1 gives a summary of error sources and the associated retrieval errors for best IWP estimate. Systematic errors are estimated in a Bayesian manner. The stated values should accordingly not be taken as "worst case" estimates, they express instead our view of the range of possible values (normally distributed). The retrieval accuracy expresses the sum of all error sources, assuming that they are independent quantities.
The error sources considered in Ekström et al. (2007) are included in Table 1 for completeness, but are all of minor importance here and are not discussed further. The impact of particle aspect ratio and orientation is small (Sect. 4.3), but not insignificant. Both random and fixed retrieval errors of $15 \%$ are assigned to the combined effect of these error sources, together with other possible microphysical uncertainties (such as, refractive index and deviation from solid particles).

Cloud inhomogeneity is assumed to be a major error source, even if Eq. (1) is applied to compensate for the neglection of horizontal variation of the ice clouds. No quantitative calculations have been performed to investigate this error source further. The error estimates given are based on Davis et al. (2006), following the discussion in Sect. 4.5. The introduction of a correction term (Eq. 1) should decrease the magnitude of this error source, and also convert it from being strongly systematic to be more random in nature, and therefore be decreased by averaging.

The second of the two dominating error sources is the assumed PSD. A detailed error analysis would require access to and analysis of large data sets of in-situ measurements, spanning all relevant atmospheric conditions. Such data are not at hand and only rough estimates can be given. An initial study (Rydberg, 2004) compared total scattering extinction for different PSDs. Focus is given to the comparison to the PSD of Donovan (2003) (D03), despite that it is determined for midlatitude conditions. This choice was made as the D03 PSD is based on remote sensing data, and should therefore be totally independent in technical aspects to MH97, derived from insitu measurements. In addition, D03 incorporates radar data that should constrain the particle size range to those of concern for sub-mm observations. It was found that replacing MH97 with D03 would change the IWP by less than $25 \%$, if the cloud ice is found at temperatures around $-40^{\circ} \mathrm{C}$. On the other hand, large differences between MH97 and D03 (and two other PSDs considered) were noted for lower temperatures $\left(-60^{\circ} \mathrm{C}\right)$, that correspond to IWP retrieval errors $>100 \%$, but it can be questioned if the D03 PSD is valid for such temperatures. Considering this discussion, 30 and $40 \%$ are adopted for the systematic and random error, respectively.

The high PSD retrieval error originates in the fact that any remote sensing technique limited to a single wavelength range will only be sensitive to a part of the cloud ice particle size spectrum, where short wavelengths will give sensitivity to small particles, and vice versa. If the purpose is to estimate the ice mass, the wavelength employed should be selected in such way that the highest sensitivity is given to the particle size region holding the main part of the total mass. Figure 11 shows the mass distribution for some conditions representing thinner and thicker clouds at temperatures found in the upper tropical troposphere. The size range of interest differs between the cases, but a dominating part of the ice mass is found in particles having a diameter of 35-400 $\mu \mathrm{m}$, which corresponds quite closely to the peak area of the gamma PSD 
for maximum sensitivity for Odin-SMR (Sect. 4.3). This indicates that, despite that the IWP retrievals presented are estimated to have important errors due to PSD assumptions, the situation is not better for retrievals using other wavelength regions.

\section{Conclusions}

A first cloud ice retrieval scheme for Odin-SMR has been developed. Observation data are taken from the two bands of the stratospheric mode, 501 and $544 \mathrm{GHz}$, where, so far, only spectra with tangent altitudes below $9 \mathrm{~km}$ are considered. The first step of the retrieval is to determine, for each band, the brightness temperature depression $\left(\Delta \mathrm{T}_{\mathrm{b}}\right)$ induced by ice clouds, compared to the corresponding clear-sky situation. This step is based on the work of Ekström et al. (2007). For the purpose of cloud detection a simple $\Delta \mathrm{T}_{\mathrm{b}}$ threshold is applied. The main limiting factor for the cloud detection is a random calibration error causing a $\sim 2 \mathrm{~K}$ uncertainty in $\Delta \mathrm{T}_{\mathrm{b}}$.

The measurements also allow retrieval of the ice water path (IWP) above $\approx 12.5 \mathrm{~km}$. As Odin-SMR is used here more in the sense of a down-looking instrument rather than as a limb sounder, information from 501 and $544 \mathrm{GHz}$ must be combined. The $501 \mathrm{GHz}$ band exhibits the strongest cloud signal, and the practical contribution of the $544 \mathrm{GHz}$ data is to constrain the cloud altitude. The sensitivity is such that there is a full response to cloud ice above $14 \mathrm{~km}$, but decreasing below to reach zero at $11.5 \mathrm{~km}$. The detection threshold corresponds to an IWP of $\sim 4 \mathrm{~g} / \mathrm{m}^{2}$. The dynamic range of the retrievals extends up to at least $500 \mathrm{~g} / \mathrm{m}^{2}$. The dominating error sources for the IWP retrieval are that a particle size distribution (PSD) must be assumed and that full account for cloud horizontal structures can not be taken. The later effect stems from the fact that radiative transfer calculations assume 1-D conditions. A correction term for the neglected 3-D effects is suggested. A detailed analysis is not possible for either PSD or 3-D issues, as data to evaluate the errors for different conditions are lacking. At this point the systematic and random retrieval errors are set to 30 and $40 \%$, respectively, for both effects. The coming release of CloudSat data could be an opportunity to incorporate 3-D effects more correctly in the analysis.

A firm lower limit for the retrieved cloud ice column can be obtained by assuming a PSD that maximises the extinction cross-section for wavelengths used, and by not performing a 1-D/3-D correction. The difference between minimum and best estimate decreases with increasing IWP. For the areas with thicker ice clouds, the minimum estimate of mean IWP is a factor $4-8$ below the best estimate.

A simple comparison to the ice fields in ECMWF analyses and the ECHAM GCM is made, that gives results consistent with a similar comparison involving Aura MLS (Li et al., 2005). Both the Odin-SMR and Aura MLS retrievals indicate

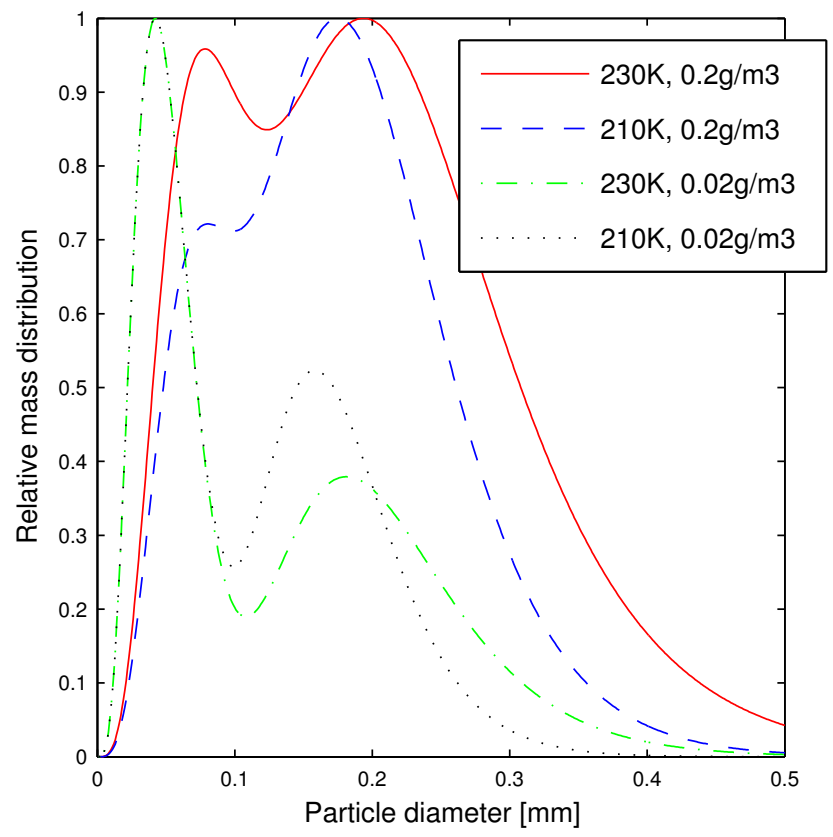

Fig. 11. Distribution of mass, as a function of particle size for different temperatures and ice water content. The MH97 PSD is assumed. Each distribution is normalised to its maximum value.

that atmospheric models show tendencies to underestimate the amount of cloud ice in the tropical upper troposphere. For example, already the minimum Odin-SMR IWP over central Africa is above the GCM data. However, the high retrieval uncertainties so far limit a more detailed investigation of the performance of the models. Other existing satellite data are however not better in this respect. On the contrary, sub-mm radiometry is an advantageous approach for measuring cloud ice contents, but Odin-SMR lacks the broad coverage of the $\mathrm{mm} / \mathrm{sub}-\mathrm{mm}$ region that should be used by a dedicated cloud ice instrument (Evans et al., 2002).

It has been shown that the impact of scattering on OdinSMR spectra is understood, and valuable climate data can be extracted. This justifies continued efforts to also make use of the cloud ice information found in spectra with higher tangent altitudes. Such a development should result in a higher sensitivity to clouds with low IWP values and an improved vertical resolution.

Acknowledgements. This work is based in various ways on efforts made by persons inside the Odin-SMR retrieval group. Essential contributions by the ARTS community are also acknowledged. ECMWF and ECHAM data were generously provided by A. Tompkins and U. Lohmann, respectively. Financial support was provided by the Swedish National Space Board and the Swedish National Graduate school of Space Technology. Comments and suggestions given during the open discussion in ACPD by an anonymous referee, C. Davis and D. Wu were very valuable for preparing the final manuscript. 
Edited by: U. Pöschl

\section{References}

Buehler, S. A., Eriksson, P., Kuhn, T., von Engeln, A., and Verdes, C.: ARTS, the Atmospheric Radiative Transfer Simulator, J. Quant. Spectrosc. Radiat. Transfer, 91, 65-93, doi:10.1016/j.jqsrt.2004.05.051, 2005.

Corti, T., Luo, B. P., Fu, Q., Vömel, H., and Peter, T.: The impact of cirrus clouds on tropical troposphere-to-stratosphere transport, Atmos. Chem. Phys., 6, 2539-2547, 2006,

http://www.atmos-chem-phys.net/6/2539/2006/.

Davis, C., Emde, C., and Harwood, R.: A 3-D polarized reversed Monte Carlo radiative transfer model for $\mathrm{mm}$ and sub-mm passive remote sensing in cloudy atmospheres, IEEE Trans. Geosci. Rem. Sens., 43, 1096-1101, 2005a.

Davis, C. P., Wu, D. L., Emde, C., Jiang, J. H., Cofield, R. E., and Harwood, R. S.: Cirrus induced polarization in $122 \mathrm{GHz}$ Aura Microwave Limb Sounder radiances, Geophys. Res. Lett., 32, L14806, doi:10.1029/2005GL022681, 2005 b.

Davis, C. P., Evans, K. F., Buehler, S. A., Wu, D. L., and Pumphrey, H. C.: 3-D polarised simulations of space-borne passive $\mathrm{mm} / \mathrm{sub}-$ mm midlatitude cirrus observations: a case study, Atmos. Chem. Phys. Discuss., 6, 12 701-12 728, 2006.

Donovan, D. P.: Ice-cloud effective particle size parameterization based on combined lidar, radar reflectivity, and mean Doppler velocity measurements, J. Geophys. Res., 108(D18), 4573, doi:10.1029/2003JD003469, 2003.

Ekström, M., Eriksson, P., Rydberg, B., and Murtagh, D.: First Odin sub-mm retrievals in the tropical upper troposphere: humidity and cloud ice signals, Atmos. Chem. Phys., 7, 459-469, 2007, http://www.atmos-chem-phys.net/7/459/2007/.

Emde, C., Buehler, S. A., Davis, C., Eriksson, P., Sreerekha, T. R., and Teichmann, C.: A polarized discrete ordinate scattering model for simulations of limb and nadir longwave measurements in 1D/3D spherical atmospheres, J. Geophys. Res., 109(D24), D24 207, doi:10.1029/2004JD005140, 2004a.

Emde, C., Buehler, S. A., Eriksson, P., and Sreerekha, T. R.: The effect of cirrus clouds on limb radiances, J. Atmos. Res., 72, 383401, doi:10.1016/j.atmosres.2004.03.023, 2004b.

Evans, K. F., Walter, S. J., Heymsfield, A. J., and Deeter, M. N.: Modeling of submillimeter passive remote sensing of cirrus clouds, J. Appl. Meteorol., 37, 184-205, 1998.

Evans, K. F., Walter, S. J., Heymsfield, A. J., and McFarquhar, G. M.: Submillimeter-wave cloud ice radiometer: Simulations of retrieval algorithm performance, J. Geophys. Res., 107, 2.12.21, 2002.

Frisk, U., Hagström, M., Ala-Laurinaho, J., Andersson, S., Berges, J. C., Chabaud, J. P., Dahlgren, M., Emrich, A., Florén, H. G., Gredrixon, M., Gaier, T., Haas, R., Hirvonen, T., Hjalmarsson, A., Jakobsson, B., Jukkala, P., Kildal, P. S., Kollberg, E., Lassing, J., Lecacheux, A., Lehikoinen, P., Lehto, A., Mallat, J., Marty, C., Michet, D., Narbonne, J., Nexon, M., Olberg, M., Olofsson, A. O. H., Olofsson, G., Origné, A., Petersson, M., Piironen, P., Pons, R., Pouliquen, D., Ristorcelli, I., Rosolen, C., Rouaix, G., Räisänen, A. V., Serra, G., Sjöberg, F., Stenmark, L., Torchinsky, S., Tuovinen, J., Ullberg, C., Vinterhav, E., Wadefalk, N., Zirath, H., Zimmermann, P., and Zimmermann, R.: The Odin satellite I.
Radiometer design and test, Astron. Astrophys., 402, L27-L34, doi:10.1051/0004-6361:20030335, 2003.

Fueglistaler, S. and Baker, M. B.: A modelling study of the impact of cirrus clouds on the moisture budget of the upper troposphere, Atmos. Chem. Phys., 6, 1425-1434, 2006,

http://www.atmos-chem-phys.net/6/1425/2006/.

Genio, A. D. D. and Kovari, W.: Climatic properties of tropical convection under varying environmental conditions, J. Climate, 15, 2597-2615, 2002.

Heymsfield, A. J.: Properties of tropical and midlatitude ice cloud particle ensembles, Part II: Applications for mesoscale and climate models, J. Atmos. Sci., 60, 2592-2611, 2003.

Heymsfield, A. J. and Platt, C. M. R.: A parameterization of the particle size spectrum of ice clouds in terms of the ambient temperature and the ice water content, J. Atmos. Sci., 41, 846-855, 1984.

Heymsfield, A. J., Bansemer, A., Field, P. R., Durden, S. L., Stith, J. L., Dye, J. E., Hall, W., and Grainger, C. A.: Observations and parameterizations of particle size distributions in deep tropical cirrus and stratiform precipitating clouds: Results from in situ observations in TRMM field campaigns., J. Atmos. Sci., 59, 3457-3491, 2002.

Heymsfield, A. J., Matrosov, S., and Baum, B.: Ice water path - optical depth relationships for cirrus and deep stratiform ice cloud layers, J. Appl. Meteorol., 42, 1369-1390, 2003.

Hong, G., Heygster, G., Miao, J., and Kunzi, K.: Detection of tropical deep convective clouds from AMSU-B water vapor channels measurements, J. Geophys. Res., 110, D05 205, doi:10.1029/2004JD004949, 2005.

IPCC: Climate change 2001: The scientific basis, Cambridge University Press, Cambridge, UK, 2001.

Li, J. L., Waliser, D. E., Jiang, J., Wu, D. L., Read, W., Waters, J. W., Tompkins, A. M., Donner, L. J., Chern, J. D., Tao, W. K., Atlas, R., Gu, Y., Liou, K. N., Genio, A. D., Khairoutdinov, M., and Gettelman, A.: Comparisons of EOS MLS cloud ice measurements with ECMWF analyses and GCM simulations: Initial results, Geophys. Res. Lett., 32, L18 710, doi:10.1029/2005GL023788, 2005.

McFarquhar, G. M. and Heymsfield, A. J.: Parameterization of tropical cirrus ice crystal size distribution and implications for radiative transfer: Results from CEPEX, J. Atmos. Sci., 54, 21872200, 1997.

Mishchenko, M. I. and Travis, L. D.: Capabilities and limitations of a current FORTRAN implementation of the T-matrix method for randomly oriented rotationally symmetric scatterers, J. Quant. Spectrosc. Radiat. Transfer, 60, 309-324, 1998.

Murtagh, D., Frisk, U., Merino, F., Ridal, M., Jonsson, A., Stegman, J., Witt, G., Eriksson, P., Jiménez, C., Megie, G., de La Noë, J., Ricaud, P., Baron, P., Pardo, J. R., Hauchcorne, A., Llewellyn, E. J., Degenstein, D. A., Gattinger, R. L., Lloyd, N. D., Evans, W. F. J., McDade, I. C., Haley, C., Sioris, C., von Savigny, C., Solheim, B. H., McConnell, J. C., Strong, K., Richardson, E. H., Leppelmeier, G. W., Kyrölä, E., Auvinen, H., and Oikarinen, L.: An overview of the Odin atmospheric mission, Can. J. Phys., 80, 309-319, 2002.

Nordh, H. L., von Schéele, F., Frisk, U., Ahola, K., Booth, R. S., Encrenaz, P. J., Hjalmarson, A., Kendall, D., Kyrölä, E., Kwok, S., Lecacheux, A., Leppelmeier, G., Llewellyn, E. J., Mattila, K., Mégie, G., Murtagh, D., Rougeron, M., and Witt, G.: The 
Odin orbital observatory, Astron. Astrophys., 402, L21-L25, doi:10.1051/0004-6361:20030334, 2003.

Okhert-Bell, M. E. and Hartmann, D. L.: The effect of cloud type on earth's energy balance: Results for selected regions, J. Atmos. Sci., 5, 1157-1171, 1992.

Rydberg, B.: Submillimeter-wave radiometric measurements of cirruscloud ice, Master's thesis, Chalmers University of Technology, Gothenburg, Sweden, 2004.

Stephens, G. L., Vane, D. G., Boain, R. J., Mace, G. G., Sassen, K., Wang, Z. E., Illingworth, A. J., O’Connor, E. J., Rossow, W. B., Durden, S. L., Miller, S., Austin, R. T., Benedetti, A., and Mitrescu, C.: The CloudSat mission and the A-train - A new dimension of space-based observations of clouds and precipitation, Bull. Amer. Meteorol. Soc., 83, 1771-1790, 2002.

Stubenrauch, C. J., Rossow, W. B., Chruy, F., Scott, N. A., and Chédin, A.: Clouds as seen by satellite sounders (3I) and imagers (ISCCP): I-Evaluation of cloud parameters, J. Climate, 12, 2189 2213, 1999.
Urban, J., Lautié, N., Le Flochmoën, E., Jiménez, C., Eriksson, P., Dupuy, E., El Amraoui, L., Ekström, M., Frisk, U., Murtagh, D., de La Noë, J., Olberg, M., and Ricaud, P.: Odin/SMR limb observations of stratospheric trace gases: Level 2 processing of $\mathrm{ClO}, \mathrm{N}_{2} \mathrm{O}, \mathrm{O}_{3}$, and $\mathrm{HNO}_{3}$., J. Geophys. Res., 110, D14 307, doi:10.1029/2004JD005741, 2005.

Winker, D. M. and Trepte, C. R.: Laminar cirrus observed near the tropical tropopause by LITE, Geophys. Res. Lett., 25, 33513354, 1998.

Wu, D. L., Read, W. G., Dessler, A. E., Sherwood, S. C., and Jiang, J. H.: UARS/MLS cloud ice measurements: Implications for $\mathrm{H}_{2} \mathrm{O}$ transport near the tropopause, J. Atmos. Sci., 62, 518-530, 2005.

Wu, D. L., Jiang, J. H., and Davis, C. P.: EOS MLS cloud ice measurements and cloudy-sky radiative transfer model, IEEE Trans. Geosci. Rem. Sens., 44, 1156-1165, 2006. 